\title{
Espaços e Ações das Bibliotecas Escolares no Âmbito do Plano de Ações Articuladas (PAR) do Município de Dourados, MS
}

\author{
Spaces and actions of school libraries in the Plano f Articulated Actions from the city of \\ Dourados, $M S$
}

\begin{abstract}
Maria Isabel Soares Feitosa
Coordenadoria de Serviços de Bibliotecas - Seção de Processamento Técnico da Universidade Federal da
Grande Dourados.

E-mail: isabel.ufgd@gmail.com

Maria do Carmo Caetano

Coordenadoria de Serviços de Bibliotecas - Seção de Atendimento da Universidade Federal da Grande

Dourados.

E-mail: mariacaetano@ufgd.edu.br
\end{abstract}

\begin{abstract}
Resumo
O estudo em pauta objetiva analisar a condução do Plano de Ações Articuladas (PAR), no $2^{\circ}$ Ciclo (2011-2014) referente à infraestrutura física e pedagógica das bibliotecas escolares da Rede Municipal de Ensino de Dourados/MS. O desafio consiste em conhecer o desenvolvimento do processo e quais as implicações para a qualidade da educação do município. Estudos apontam fragilidades e dificuldades de compreensão dos requisitos contidos no PAR, resultantes do desconhecimento do bojo do programa, da falta de participação coletiva e na elaboração e acompanhamento do PAR, e de abertura no instrumento para a inclusão das especificidades das escolas. Dados demonstram que o município de Dourados desenvolveu diversas ações relacionadas às propostas na Dimensão 4 do PAR - Infraestrutura e Recursos pedagógicos, resultando na melhoria da qualidade das bibliotecas existentes, na construção e na ampliação de espaços específicos para novas bibliotecas. Na visão dos gestores tais ações contribuíram para a melhoria do processo de ensino de modo geral.
\end{abstract}

Palavras-chave: Políticas educacionais. Plano de Ações Articuladas (PAR) - Bibliotecas escolares.

\begin{abstract}
The study aims to analyze the conducting the Plan for Linked Actions (PAR), on the 2nd cycle (2011-2014) regarding the physical infrastructure and the pedagogical school libraries of the Municipal School of Dourados/MS. The challenge is to know the development of the process and what are the implications for the quality of the education in the municipalities. Studies show weaknesses and difficulties in understanding the requirements contained in the PAR, resulting from the lack of bulging of the program, the lack of collective participation and in the preparation and monitoring of the pair, and openness in the instrument to inclusion the specificities of the schools. Data show that the city of Dourados developed various actions related to the proposals in dimension 4 of the PAR - infrastructure and educational resources, resulting in the improvement of the quality of existing libraries, in construction and in the expansion of specific spaces for new libraries. In the managers'view such actions have contributed to the improvement of the teaching process in general.
\end{abstract}

Keywords: Educational policies. Plan Articulated Actions (PAR). School Libraries.

Bibl. Esc. em R., Ribeirão Preto, v. 6, n. 1, p. 1-17, 2017. 
Espaços e Ações das Bibliotecas Escolares no Âmbito do Plano de Ações Articuladas (PAR) do Município de Dourados, MS

\section{Introdução}

O presente estudo, vinculado a uma pesquisa em rede ${ }^{1}$ interinstitucional denominada: “Gestão das políticas educacionais no Brasil e seus mecanismos de centralização e descentralização: o desafio do PAR em escolas de ensino fundamental" tem como principal objetivo analisar de forma reflexiva o processo de condução das ações do Plano de Ações Articuladas, no $2^{\circ}$ Ciclo, Dimensão 4 , referente a infraestrutura física e pedagógica das bibliotecas escolares da Rede Municipal de Ensino de Dourados, estado de Mato Grosso do Sul.

O recorte temporal ficou circunscrito ao o segundo ciclo do PAR (2011-2014) instigado pelo fato de que pesquisas anteriores de Amorim (2011), Ferreira (2014) e, Souza (2011) terem constatado que na maioria dos municípios brasileiros o desenvolvimento do primeiro ciclo do PAR (2007-2010) na realidade não aconteceu como deveria. Essas pesquisas dão conta que houve certos equívocos e desentendimentos quanto as tarefas dos comitês locais, que por exigências da legislação referente ao PAR, foram especialmente instituídos para a inclusão de informações sobre a situação/necessidades existentes nas redes de ensino dos municípios brasileiros.

Considerando as prerrogativas contidas na Dimensão 4, do segundo ciclo do PAR (2011-2014) destaca-se o quesito infraestrutura das bibliotecas escolares municipais douradenses, por isso, torna-se relevante investigar: a) quais os critérios usados para a realização dos diagnósticos da situação escolar sobre as bibliotecas escolares; b) quais as ações que foram propostas para o desenvolvimento qualitativo das bibliotecas; c) quais as ações que foram efetivamente concretizadas neste planejamento e, d) quais as implicações de tais ações na melhoria da capacidade de planejamento do sistema educacional e na contribuição da qualidade da educação escolar.

A discussão e a análise destas questões passam por concepções teóricas que consideram a educação escolar como um processo histórico social, considerando que:

pensar a qualidade social da educação implica assegurar um processo pedagógico pautado pela eficiência, eficácia e efetividade social, de modo a contribuir com a

\footnotetext{
${ }^{1}$ Realizada em parceria com as seguintes universidades: Universidade Federal de Mato Grosso do Sul (UFMS), Universidade Estadual de Mato Grosso do Sul (UEMS), Universidade Católica Dom Bosco (UCDB) e Universidade Federal da Grande Dourados (UFGD), financiada pela FUNDECT, sob coordenação da professora doutora Marília Fonseca. (UnB)
} 
Maria Isabel Soares Feitosa e Maria do Carmo Caetano

melhoria da aprendizagem dos educandos, em articulação a melhoria das condições de vida e de formação da população (DOURADO, 2010, p. 940).

Entre os principais instrumentos de pesquisa estão: o levantamento bibliográfico; a pesquisa documental e as entrevistas. O levantamento bibliográfico permitiu o embasamento conceitual sobre as políticas educacionais, especialmente, sobre a constituição do PAR, seus princípios e diretrizes no pleito de uma educação de qualidade.

A pesquisa documental serviu como fundamentação no que tange a legitimação das políticas educacionais, principalmente, para a compreensão das ações ou subações que foram desenvolvidas em prol da constituição das bibliotecas escolares da Rede Municipal de Ensino de Dourados/MS como incremento para a melhoria da qualidade educacional.

As entrevistas foram realizadas com auxílio de um roteiro de questões semiestruturadas no intuito de possibilitar que a pessoa, quando inquerida, pudesse demonstrar suas concepções e informações de um jeito mais aberto e tranquilo. Notoriamente, as entrevistas foram realizadas com pessoas responsáveis pelo acompanhamento das ações referentes a Dimensão 4 do PAR no se refere a infraestrutura e recursos pedagógicos.

\section{A biblioteca frente às novas exigências de formação escolar}

Expressões como "sociedade da informação", "explosão da informação", "múltiplas competências" são termos que, de modo direto, influenciam os objetivos e fins da educação. Os novos desafios das demandas sociais, a valorização do conhecimento acadêmico, a multiplicidade de exigências do mercado de trabalho traz para a escola novas exigências na formação do sujeito como pessoa e como trabalhador.

A partir de 1990, "um novo paradigma educacional emerge, centrado no aluno e na aprendizagem. A educação para a autonomia, o espírito crítico e a aprendizagem ao longo da vida ocupam um lugar central nas mais recentes discussões sobre as novas funções da escola" (SANTOS, 2011, p. 5). Esse novo paradigma passou a fazer parte das agendas das políticas públicas educacionais nacionais e internacionais, houve uma efervescência de ideias em prol da melhoria da formação escolar em diversos contextos em desenvolvimento social e econômico.

Os compromissos internacionais via Banco Mundial reafirmavam a necessidade de promover infraestrutura técnica, financeira e material na busca da transformação da educação

Bibl. Esc. em R., Ribeirão Preto, v. 6, n. 1, p. 1-17, 2017. 
Espaços e Ações das Bibliotecas Escolares no Âmbito do Plano de Ações Articuladas (PAR) do Município de Dourados, MS

desses contextos. No elenco de prioridades estavam as propostas de investimentos em insumos educacionais como bibliotecas, livros didáticos e materiais tecnológicos. (FONSECA, 2009). Desse modo, no quesito infraestrutura técnica e pedagógica, a biblioteca escolar tomou importância por ser considerada uma das necessidades básicas do atendimento escolar. A biblioteca escolar passou a ser considerada instrumento de socialização e democratização do conhecimento científico por intermédio das práticas da leitura, bem como, espaço de informação e de lazer.

Diante das exigências dos compromissos firmados neste período, em 1997 o MEC criou o Programa Nacional Biblioteca na Escola (PNBE) ${ }^{2}$ que segundo o Portal do MEC, teve como objetivos a promoção do acesso e do incentivo a leitura por meio da distribuição de conjunto de obras de literatura, de pesquisa e de referência. Constitui-se em uma iniciativa de ampliação das condições de leitura na escola e de oferecimento de fontes de pesquisas para estudantes e professores. São medidas que buscam a melhoria na qualidade do ensinoaprendizagem no contexto escolar, visando atender as diversas especificidades que compõem a educação em sua totalidade.

No entanto, pesquisas de Paiva e Berenblum (2009) apontam inúmeros problemas no desenvolvimento das ações e estratégias do programa nacional de bibliotecas escolares. Começando pela sua conformação o PNBE, enquanto programa:

\begin{abstract}
integrado por vários subprogramas de distribuição de kits de livros com diferentes finalidades e objetivos referiu-se essencialmente à aquisição e à distribuição de coleções de literatura e obras de referência para alunos e professores [...]. O volume de obras distribuído e o investimento total realizado contrastavam, muitas vezes, principalmente quanto ao uso e ao destino dos livros e com a situação estrutural das escolas, [...]. Embora o Programa tivesse nascido com a finalidade de equipar as escolas com livros para as bibliotecas escolares, em acervos coletivos, em dado momento os investimentos destinaram-se a coleções pessoais recebidas por poucos alunos, em relação ao universo de matrículas. Praticamente, o PNBE manteve-se apenas como um grande programa de distribuição de livros, como se a existência de acervos (de qualidade) fosse o caminho natural de formação de leitores nas escolas públicas brasileiras, sem prever apoio algum a projetos de formação continuada de professores com o foco na leitura literária (PAIVA; BERENBLUM, 2009, p. 184).
\end{abstract}

As situações estruturais das escolas, marcadas pelas desigualdades regionais, foram apontadas como fatores cruciais para o desenvolvimento do PNBE dentro das escolas. A maioria das escolas não dispunha de bibliotecas ou lugar adequado para receber e usufruir pedagogicamente dos livros. Em algumas escolas os materiais recebidos permaneciam em

\footnotetext{
${ }^{2}$ Programa do governo federal criado em 1997, sob gerência do FNDE com objetivos de distribuir obras literárias, pedagógicas e de referências para a educação infantil, o ensino fundamental, o ensino médio e o EJA. Até 2014 já tinha atendido $65 \%$ dos municípios brasileiros.
}

Bibl. Esc. em R., Ribeirão Preto, v. 6, n. 1, p. 1-17, 2017 
Maria Isabel Soares Feitosa e Maria do Carmo Caetano

lugares impróprios, encaixotados e guardados em armários fechados. Somando-se, constatouse a falta de profissionais habilitados na biblioteca, o desinteresse dos professores de Língua Portuguesa no envolvimento com as ações de incentivo à leitura, a falta de formação dos professores para trabalhar com os insumos literários, a insuficiência de qualidade e de quantidade de livros e outros materiais que poderiam incentivar o gosto pela leitura.

Perante o quadro de deficiências físicas e pedagógicas da maioria das escolas públicas brasileiras, os referidos autores consideram que o PNBE, que poderia ser uma política de incentivo a formação de leitores em grande escala, apenas, se tornou e uma política de distribuição de livros, como se tal fato garantisse a requerida formação. Na realidade, não se levou em conta critérios fundamentais como as condições, as diferenças e as necessidades e os desafios sociais dos processos educativos das escolas públicas. Como resultado do descuido com estes critérios, pode-se afirmar que o PNBE não promoveu impactos relevantes e transformadores no processo de ensino e aprendizagem da leitura e da escrita, visto que, "qualquer processo educativo que não seja capaz de renovar-se de acordo com as novas exigências impostas por desafios sociais, [...] pode perder sua autenticidade e seu poder transformador" (PAIVA, BERENBLUM, 2009, p. 184).

No sentido de reverter tal quadro no ano de 2010 foi sancionada a Lei 12.244 que impunha responsabilidades aos sistemas de ensino na implantação de bibliotecas em todas as escolas públicas do país, fazendo menção às exigências de profissionais bibliotecários para atuarem no âmbito das bibliotecas escolares. A previsão para efetivação dos itens contidos nos artigos desta Lei tem prazo máximo estipulado em 10 anos, ou seja, até o ano de 2.020.

De acordo com a Lei 12.244/2010 cabe aos sistemas de ensino providências em relação ao desenvolvimento de suas coleções:

[...] acervo de livros na biblioteca de, no mínimo, um título para cada aluno matriculado, cabendo ao respectivo sistema de ensino determinar a ampliação deste acervo conforme sua realidade, bem como divulgar orientações de guarda, preservação, organização e funcionamento das bibliotecas escolares. [...] esforços progressivos para que a universalização das bibliotecas escolares, nos termos previstos nesta Lei, seja efetivada num prazo máximo de dez anos, respeitada a profissão de Bibliotecário, disciplinada pelas Leis $\mathrm{n}^{\text {os }} 4.084$, de 30 de junho de 1962 , e 9.674, de 25 de junho de 1998 (BRASIL, 2010).

A lei determina responsabilidades para os sistemas de ensino em providenciar medidas relacionadas às instalações físicas e pedagógicas das bibliotecas escolares. Então se torna necessário pensar como esses sistemas atuam e atuarão no desenvolvimento dos seus projetos, programas e estratégias relativas à implantação de bibliotecas escolares até o ano de 2020.

Bibl. Esc. em R., Ribeirão Preto, v. 6, n. 1, p. 1-17, 2017. 
Espaços e Ações das Bibliotecas Escolares no Âmbito do Plano de Ações Articuladas (PAR) do Município de Dourados, MS

Entendendo que as bibliotecas escolares contribuem para a melhoria da qualidade da educação e para se fazer cumprir as exigências impostas pela referida Lei (12.244/2010), o Plano de Ações Articuladas (PAR) integra ações e subações que dizem respeito diretamente as bibliotecas escolares e salas de leitura. Importa, no entanto, dar a conhecer minimamente a constituição do PAR.

\section{O Plano de Ações Articuladas (PAR) como instrumento de planejamento educacional}

Dando prosseguimento ao desenvolvimento das políticas públicas na área da educação, o governo federal, via MEC, criou o Plano de Ações Articuladas visando garantir auxílio técnico e financeiro para os estados e municípios melhorarem a qualidade de ensino escolar. O grande objetivo é o fortalecimento qualitativo dos sistemas de ensino nos estados e municípios brasileiros.

Conceitualmente, pode-se entender o PAR como um planejamento dinâmico da educação realizado pelos Municípios, Estados e Distrito Federal. A elaboração do PAR pelos municípios é requisito necessário para o recebimento de assistência técnica e financeira do MEC por meio do Fundo Nacional para o Desenvolvimento da Educação (BRASIL, 2011b).

As pesquisadoras Ferreira e Fonseca (2013) consideram o PAR como ferramenta indutora de:

políticas públicas que objetiva o fortalecimento dos sistemas locais, proporcionando maior autonomia na gestão da educação, assim como nas políticas de gestão democrática $[\ldots]$ o PAR é uma ferramenta de planejamento, de operacionalização e de avaliação das políticas educacionais criadas dentro dos moldes de um governo federativo (FERREIRA; FONSECA, 2013, p. 288).

O MEC qualifica, o PAR como um instrumento de planejamento quadrienal da educação, podendo ser considerado um plano estratégico de caráter plurianual e multidimensional que possibilita a conversão dos esforços e das ações do MEC, das Secretarias de Estado e Municípios, num Sistema Nacional de Educação. Um plano que abarca quatro dimensões do processo educativo: 1- A gestão educacional; 2 - Formação de Professores e dos Profissionais de Serviço e Apoio Escolar; 3 - Práticas Pedagógicas e Avaliação e 4 - Infraestrutura física e recursos pedagógicos (BRASIL, 2011b).

A dinâmica do PAR se desenvolve em três etapas: o diagnóstico da realidade da educação, a elaboração do plano e a análise técnica. O diagnóstico minucioso da situação da 
Maria Isabel Soares Feitosa e Maria do Carmo Caetano

realidade educacional local resultará num conjunto de informações que serão cadastradas numa plataforma própria, online, denominada Sistema Integrado de Planejamento, Orçamento, Finanças do Ministério da Educação (SIMEC), no módulo PAR - Plano de Metas, para que possam submeter propostas para o financiamento dos projetos para receber os recursos solicitados e permitir o acompanhamento por qualquer cidadão (BRASIL, 2011b).

A fase do diagnóstico é fundamentada por critérios de pontuação, assim definidos:

Critério de pontuação 4- a descrição aponta para uma situação positiva, ou seja, para aquele indicador não são necessárias ações imediatas. Critério de pontuação 3-a pontuação aponta para uma situação satisfatória, com mais aspectos positivos que negativos, ou seja, o Município desenvolve, parcialmente, ações que favorecem o desempenho do indicador. Critério de pontuação 2- a descrição aponta para uma situação insuficiente, com mais aspectos negativos do que positivos; serão necessárias ações imediatas e estas, poderão contar com o apoio técnico e/ou financeiro do MEC. Critério de pontuação 1-a descrição aponta para uma situação crítica, de forma que não existem aspectos positivos, apenas negativos ou inexistentes (BRASIL, 2008).

Diante da pontuação, os resultados constatados na situação local são repassados para o SIMEC (União) que disponibiliza a assistência técnica e financeira no sentido de solucionar os problemas detectados na referida fase do diagnóstico realizado. É importante salientar o caráter participativo do programa desde o envolvimento conjunto da União, dos estados e de cada município. Os trabalhos de diagnóstico, da coleta de informações e do detalhamento das ações e subações deverão ser obtidos a partir da discussão conjunta entre os membros da equipe técnica local, cuja composição deverá contemplar a presença dos gestores e técnicos das secretarias, de todos os segmentos das escolas e em suas diversas modalidades de oferta do ensino escolar (BRASIL, 2008, 2011a).

\section{A Dimensão 4 do PAR (2010-2014) e seus indicadores para a compleição das bibliotecas escolares}

Tratando especificamente dos propósitos da Dimensão 4 do PAR, no que diz respeito a biblioteca escolar, ficou estabelecido que as Secretarias Municipais de Educação procedessem à elaboração de um plano plurianual de adequação e / ou construção de bibliotecas escolares adotando os padrões mínimos de funcionalidade e respeitando às especificidades das escolas indígenas e do campo, de acordo com as orientações do Manual dos Padrões Mínimos de Funcionamento das escolas (BRASIL, 2008).

Bibl. Esc. em R., Ribeirão Preto, v. 6, n. 1, p. 1-17, 2017. 
Espaços e Ações das Bibliotecas Escolares no Âmbito do Plano de Ações Articuladas (PAR) do Município de Dourados, MS

Como já referido o presente estudo intenciona analisar a condução do Plano de Ações Articuladas (PAR), no $2^{\circ}$ Ciclo (2011-2014) referente à infraestrutura física e pedagógica das bibliotecas escolares da Rede Municipal de Ensino de Dourados/MS. O desafio consiste em conhecer o desenvolvimento de ações e subações propostas no PAR para a melhoria das bibliotecas escolares enquanto contribuição para a qualidade da educação do município.

O período de 2011 a 2014 correspondeu ao $2^{\circ}$ Ciclo do PAR e, passou por reformulações nas áreas e indicadores. Dada sua dinamicidade, e, atendendo as características próprias de um planejamento estratégico foram criadas novas propostas de intervenção de acordo com as necessidades levantadas e os novos objetivos a serem alcançados pelo Sistema Nacional de Educação Básica. Atualmente o PAR encontra-se no seu $3^{\circ}$ ciclo (2015-2018).

Num breve relato sobre o primeiro ciclo do PAR (2007-2010), compreende-se que o mesmo foi marcado pelos equívocos no entendimento das propostas por parte das pessoas incumbidas de participação no diagnóstico até a inclusão de dados no SIMEC. De acordo com pesquisas de Amorim (2011) a implantação do PAR no município de Dourados chegou como um projeto pronto sobre as informações que deveriam ser consideradas pela Secretaria Municipal de Ensino. Nos formulários já vinham determinados quais os quesitos que deveriam ser avaliados de acordo com os indicadores propostos não dando margens para a inclusão de necessidades específicas de cada escola.

A falta de entendimento veio do desconhecimento e da falta de clareza sobre o que seriam os princípios do programa, seus indicadores, ações e subações. Em relação à exigência de participação de os processos educativos foi constatado que poucas pessoas tiveram envolvimento no "diagnóstico" e na inclusão das informações no SIMEC. Desse modo, entende-se que na execução das etapas de trabalho não houve um processo participativo, mas, ações isoladas de determinadas pessoas indicadas para tal tarefa (AMORIM, 2011).

De forma geral, o primeiro ciclo do PAR (2007-2010) no município de Dourados, MS pode ser considerado como um período demarcado pela precariedade nas informações e nos resultados, portanto, não poderia influenciar positivamente na qualidade educacional do município.

Para o segundo ciclo do PAR (2011-2014) houve um tempo de revisão e de reelaboração de novas propostas de trabalho. Os indicadores do $2^{\circ}$ ciclo, retirados do SIMEC (2011-2014), demonstram que em relação às instalações físicas e gerais das bibliotecas 
Maria Isabel Soares Feitosa e Maria do Carmo Caetano

escolares de Dourados, quando na fase do novo diagnóstico, continuava apresentando os mesmos índices do primeiro ciclo no INDICADOR I, que seria a NOTA I, denotando que a situação estava crítica em relação ao número de escolas com espaços próprios para bibliotecas, ainda, com a falta de qualidade pedagógica das bibliotecas existentes.

No sentido da existência de recursos pedagógicos condizentes com as demandas do processo pedagógico de cada escola, o INDICADOR I aponta a NOTA 2, o que significa que o acervo continuava inadequado para o atendimento das necessidades dos professores e alunos. Quer dizer que o município deveria promover investimentos na aquisição de materiais renovados quantitativos e qualitativos de acordo com as exigências do currículo escolar municipal, bem como, nacional.

Em referência aos dados da elaboração e organização das práticas pedagógicas de leitura ou da existência de programas de incentivo a leitura, o INDICADOR 4 recebeu NOTA 2, indicando que apenas $50 \%$ das escolas da rede possuíam projetos de leitura em andamento. O investimento neste quesito passa pela necessidade de formação dos profissionais, do incentivo ao desenvolvimento de diversos projetos, bem como, pelo investimento no acervo literário, no uso das tecnologias e outras ações que possam incentivar na formação de leitores competentes.

$\mathrm{Na}$ análise dos dados foi constatado que nada foi mudado de um ciclo para outro em relação à construção, ampliação e reformas dos espaços destinados ao funcionamento das bibliotecas nas escolas. Como resultado do diagnóstico realizado no início do segundo ciclo (2011-2014) foi constatado que os espaços usados como bibliotecas nas escolas eram insuficientes, continuavam inapropriados, subutilizados e marcados pela carência de profissionais capacitados na área. Os acervos se encontravam desatualizados e com materiais insuficientes em quantidade e em qualidade, portanto, não demonstravam capacidades para contribuir com a tão almejada qualidade da educação do município.

Diante da situação, seriam necessários mais investimentos financeiros e técnicos na construção e adequação dos espaços físicos, na adequação dos mobiliários e na ampliação dos acervos, na formação de profissionais e em recursos tecnológicos para todas as bibliotecas das escolas.

Assim, a partir do ano de 2012 a realidade das bibliotecas escolares douradenses passou por algumas mudanças, em vistas, do atendimento das prerrogativas do PAR relativas 
Espaços e Ações das Bibliotecas Escolares no Âmbito do Plano de Ações Articuladas (PAR) do Município de Dourados, MS

a Dimensão 4. Com base nos resultados apresentados foi dado início a elaboração e a implementação de um plano plurianual de reestruturação e manutenção das bibliotecas e salas de leituras na maioria das escolas pela Secretaria Municipal de Educação - SEMED. Conforme o plano plurianual, o município de Dourados se comprometeu a construir, reformar e mobiliar e equipar espaços com condições suficientes de funcionamento de bibliotecas nas escolas da rede municipal de ensino (COORDENADORA, 2015, entrevista).

A coordenadora do Núcleo de Biblioteca Escolar da SEMED afirma que desde 2013 diversas ações foram realizadas em função de se ter bibliotecas eficientes nas escolas municipais. Quando inquerida sobre o desenvolvimento das ações do Plano de Ações Articuladas para as bibliotecas escolares, a mesma respondeu que, atendendo os requisitos do PAR foram realizados os diagnósticos nas 45 escolas do município, sendo constados diversos problemas tais como: falta do espaço biblioteca, espaço impróprio, falta de critério na administração e utilização do acervo, falta de formação para as pessoas que trabalhavam na biblioteca, falta de mobiliário entre outros (COORDENADORA, 2015, entrevista).

Quando indagada sobre as ações que foram efetivamente concretizadas neste segundo ciclo (construções, ampliações, adaptações, acervo, formação de pessoal), a mesma afirma que:

As bibliotecas escolares passaram por reformas internas, algumas foram ampliadas,
acervos reestruturados com a aquisição de livros pelos Diretores e doação recebida
do Plano Nacional da Biblioteca Escolar. Todas as auxiliares recebem formação
continuada desde 2013: Atendimento de pessoal, Curso de LIBRAS, Projetos de
Leitura em conjunto com os professores de Língua Portuguesa, Processo de
Descarte, Restauração de obras literárias, Adequação do acervo por faixa etária,
Ética no ambiente de trabalho, Formando contadores de história
(COORDENADORA, 2015, entrevista).

Em relação às condições atuais de funcionamento das bibliotecas escolares no município a coordenadora afirmou que $90 \%$ das escolas da Rede Municipal de ensino possui o espaço próprio para a biblioteca funcionando normalmente com espaço de leitura livre, de pesquisa e com projetos de leitura em conjunto com professores de Língua Portuguesa, História, artes, língua inglesa. Para as demais escolas sem biblioteca existem os projetos de leitura denominados de Cantinho de Leitura, Mala Viajante e Baú Encantado.

Frisa-se que anteriormente ao ano de 2013 no quadro funcional da Secretaria de Educação do município de Dourados não havia a presença de bibliotecários graduados. A partir da contratação de dois profissionais para atuarem à frente do Núcleo de Bibliotecas Públicas de Dourados e das Bibliotecas Escolares da Rede Municipal de Ensino (NUBPEB) 
foi possível a organização de ações para as bibliotecas escolares douradenses que coadunaram com as necessidades apontadas no diagnóstico do PAR, dessa forma o trabalho bibliotecário especializado apresentou-se como relevante para a viabilização de ações e subações adjacentes ao segundo ciclo do PAR do município.

$\mathrm{O}$ quadro a seguir detalha as ações e subações que foram previstas para o $2^{\circ}$ segundo ciclo do PAR no que diz respeito às bibliotecas escolares das 45 escolas (urbanas, do campo, indígenas) da Rede Municipal de Ensino de Dourados:

Quadro 1 - ações e subações previstas no PAR de Dourados (2011-2014)

\begin{tabular}{|l|c|c|c|c|}
\hline AÇÕES E SUBAÇÕES PROPOSTAS & $\mathbf{2 0 1 1}$ & $\mathbf{2 0 1 2}$ & $\mathbf{2 0 1 3}$ & $\mathbf{2 0 1 4}$ \\
\hline Construção, ampliação e/ ou reformas de bibliotecas nas escolas & 0 & 44 & 70 & 70 \\
\hline Aquisição de equipamentos e recursos pedagógicos & 0 & 44 & 70 & 71 \\
\hline $\begin{array}{l}\text { Plano de renovação, ampliação e manutenção do acervo } \\
\text { bibliográfico/reuniões }\end{array}$ & 0 & 10 & 10 & 10 \\
\hline Acervo bibliográfico PNBE & 0 & 71 & 44 & 71 \\
\hline Programas de incentivo à leitura & 0 & 2 & 2 & 2 \\
\hline Qualificação de Mediadores da leitura & 1 & 1 & 3 & 1 \\
\hline
\end{tabular}

Fonte: Plano de Ações Articuladas, SEMED, Dourados, 2011

Os dados apresentados no quadro 1 demonstram que 2013 e 2014 foram programadas diversas ações e subações a favor das bibliotecas escolares, ratificando o que revelou a bibliotecária responsável pela reestruturação das bibliotecas públicas e escolares do município de que "muitas ações estão sendo trabalhadas em prol da qualidade do processo pedagógico desenvolvidos nas escolas". Tal afirmativa corrobora que a Secretaria de Educação de Dourados, MS (SEMED) tem procurado desenvolver mecanismos e estratégias para dar andamento as ações e subações colocadas no PAR como merecedoras de intervenção (técnica e financeira), no que diz respeito às bibliotecas.

Ao pesquisar o segundo ciclo do PAR no município de Dourados o estudo realizado por Feitosa (2016) constatou que a maioria dos entrevistados (técnicos, diretores, coordenadores e professores) considera que o PAR oportunizou de forma sistemática a verificação das necessidades e a ampliação das melhorias nas escolas, consequentemente, oportunizou meio para que as bibliotecas escolares se configurassem como instrumentos 
Espaços e Ações das Bibliotecas Escolares no Âmbito do Plano de Ações Articuladas (PAR) do Município de Dourados, MS

indutores do desenvolvimento qualitativo do processo de aprendizagem, principalmente, a aprendizagem da leitura e da escrita e em relação ao desenvolvimento dos projetos de leitura.

Nos dados coletados por Feitosa (2016) constatou-se que houve ampliação e construção de bibliotecas com boas condições de atendimento, de preservação do acervo, de ventilação e de iluminação. Com a visão de escola leitora o município investiu na formação de auxiliares de bibliotecas, na fomentação e modernização dos acervos. As escolas intensificaram as práticas pedagógicas por meio dos projetos de leituras, criaram os cantinhos de leitura com materiais diversificados e o mobiliário condizente com as diferentes faixas etárias dos alunos, além das rodas de conversas e de muitas outras práticas. É importante salientar que esses projetos de leitura desenvolvidos nas escolas são orientados e acompanhados pela bibliotecária-chefe da SEMED, fato configurado com assistência técnica e pedagógica do município (FEITOSA, 2016).

De acordo com a bibliotecária Coordenadora de Bibliotecas Escolares da SEMED/Dourados, em 2014, já no final do $2^{\circ}$ ciclo do PAR, a Secretaria de Educação deu andamento no projeto de Implantação do Núcleo de Bibliotecas Públicas de Dourados e Bibliotecas Escolares da Rede Municipal de Ensino - NUBPEB. Nesse projeto estão previstas ações referentes à capacitação dos servidores que atuam nas bibliotecas, informatização, restauração de obras e diversos projetos de leitura. A intenção é que até o ano de 2020 seja atingido $100 \%$ de funcionamento das bibliotecas nas escolas, seguindo a Lei 12.244/10 que determina incumbências e providências para o efetivo desenvolvimento das bibliotecas escolares em todo Brasil (COORDENADORA, 2015, entrevista).

Diante das evidências contidas nas falas dos entrevistados por Feitosa (2016) há que se considerar que, no segundo ciclo do PAR (2011-2014), o município de Dourados se prontificou a atender os princípios do Plano de Ações Articuladas e desenvolveu estratégias no sentido de melhorar a qualidade da formação dos profissionais, a qualidade das condições de trabalho e a qualidade da educação de modo geral. A partir dos princípios do PAR, houve uma configuração de melhorias nos recursos pedagógicos das escolas, especificamente, aos que se referem ao funcionamento efetivo dos recursos pedagógicos oferecidos pela biblioteca de cada escola.

No entanto, as opiniões não constituem um consenso, existem considerações de que os recursos advindos do PAR não têm conseguido atender as demandas existentes na rede municipal de ensino. A assistência técnica e financeira do MEC não tem promovido às 
Maria Isabel Soares Feitosa e Maria do Carmo Caetano

condições idealizadas ou exigidas pelos organismos internacionais como fator de qualidade da educação básica, qualidade esta, aferida pelo Índice da Educação Básica (IDEB).

A Dimensão 4 do PAR que trata sobre a Infraestrutura Física e Recursos Pedagógicos, bem como, todas as demais dimensões do PAR deveriam ter recursos compatíveis com as necessidades reais, considerando, as grandes desigualdades regionais e específicas de cada escola. Na visão de Cruz (2015), praticamente em todos os municípios:

[...] a infraestrutura do espaço escolar deixa muito a desejar, embora seja a ação mais requerida pelas secretárias de educação, como constatado no trabalho de campo. A realidade é que os repasses financeiros para esta ação são os mais altos, sendo também a área que apresenta maiores problemas no que se refere à licitação e à fiscalização (CRUZ, 2015, p.11).

Diante de tais obstáculos, ainda existem escolas que não possuem o espaço construído para a biblioteca e é rara a existência de ar condicionado e de computadores para o uso dos alunos. Os recursos pedagógicos dos acervos das bibliotecas existentes são considerados insuficientes para a crescente demanda dos projetos de leitura e das demais necessidades do alunado municipal.

De acordo com as considerações colhidas, muitos dos recursos existentes nas escolas e nas bibliotecas escolares são frutos do envolvimento de professores e alunos em festas e rifas para arrecadação de fundos. Nesses movimentos existem formas de parcerias que conseguem motivar a participação da comunidade escolar de forma efetiva.

Por certo, o PAR como política de planejamento educacional tem apresentado diversos problemas e desafios em todas as suas dimensões e fases de trabalho da elaboração até a sua implementação. O programa não tem conseguido abarcar todas as situações e condições que se apresentam nos contextos escolares. Na opinião de Souza (2011):

\footnotetext{
Um verdadeiro e consistente planejamento da educação, que evidencie políticas e ações de longo prazo no âmbito local, precisa considerar toda a educação oferecida, seja no estado ou município, para além das etapas sob responsabilidade de cada ente federativo, estabelecendo mecanismos de cooperação com União, estados e municípios e também com o segmento privado na oferta da educação escolar. O planejamento da educação precisa estar legitimado em ampla participação dos atores envolvidos e considerar também variáveis intra e extra-escolares que influenciam o processo educacional, como as condições socioeconômicas (SOUZA, 2011, p. 10).
}

Diversos pesquisadores já argumentaram sobre os pontos negativos do PAR nas suas fases de elaboração e de execução das diretrizes de trabalho. No entanto, Fonseca e Albuquerque (2012) observam avanços do PAR que vão de encontro a uma perspectiva de 
Espaços e Ações das Bibliotecas Escolares no Âmbito do Plano de Ações Articuladas (PAR) do Município de Dourados, MS

gestão municipal mais conceitual e metodológica, permitindo a planificação das ações de forma articulada e, portanto, mais orgânica e colaborativa entre os entes federativos da União.

\section{Considerações finais}

Ante as considerações discorridas neste estudo, percebe-se que o norte que conduz as políticas desenhadas para a educação brasileira tem se constituído em um caminho de desafios, esperanças, frustações e de novas perspectivas no processo de ensino escolar. Leis, Planos, Programas tem servido como pano de fundo para a criação e a recriação de políticas educacionais sempre "inovadoras", no entanto, quase nunca transformadoras. No entendimento de Paulo Freire (1996, p. 7; 38) “a prática educativa transformadora" seria no sentido de promoção da formação de sujeitos histórico-sociais, com consciência crítica e autonomia de "intervenção no mundo". Uma intervenção que aspira mudanças nas estruturas das relações humanas no que abarca os campos: da política, da economia, do trabalho e dos direitos sociais como a educação, a saúde, a moradia e outros mais.

As políticas adjacentes ao PDE, PNBE, PAR, PNE são partes integrantes das discussões atuais do sistema educativo, são apresentados como "soluções viáveis" e que de marcam influências no modo de agir dentro da escola, mesmo que a maioria dos atores envolvidos no processo (diretores, coordenadores, professores) tenha vaga compreensão sobre a consecução destes aparatos legais. Os entrevistados quando inqueridos não souberam detalhar quais as ações que foram ou poderiam ser relevantes para a melhoria da qualidade das escolas. As respostas são vagas, dizem que o PAR chegou como um programa pronto, não dando margens para análises e discussões sobre as diretrizes a serem tomadas pelas próprias escolas.

$\mathrm{Na}$ questão da infraestrutura física e pedagógica para as bibliotecas escolares tanto no primeiro (2007-2010) quanto no início do segundo ciclo (2011-2014) do PAR não houve evidências de ações ou subações contundentes direcionadas a esses aparelhos educacionais que pudessem colaborar significativamente com a melhoria na qualidade do ensino escolar. $\mathrm{O}$ fato é que a maioria das bibliotecas funcionava em espaços inadequados em termos de qualidade física, de recursos pedagógicos e de profissionais, bem como, outros departamentos como laboratórios e salas de apoio pedagógico sofrem das mesmas carências. 
Maria Isabel Soares Feitosa e Maria do Carmo Caetano

A partir do ano de 2013 (metade de segundo ciclo do PAR), os dados comprovam que diversas ações foram desenvolvidas em prol da qualidade das bibliotecas escolares do município, tais como: construções, ampliações, renovação dos acervos, formação dos profissionais. Entre ações consideradas positivas e que sustentam os acervos das bibliotecas escolares do município, o Programa Nacional Biblioteca na Escola (PNBE) foi sempre citado como importante política do governo para a melhoria da educação pela destinação de obras aos alunos e aos professores. No entanto, este programa não tem conseguido atender as demandas existentes nas escolas do município, bem como, na educação em geral.

Na concepção da Coordenadora do Núcleo de Bibliotecas Escolares da Secretaria Municipal de Dourados houve significativas melhorias para as bibliotecas do município, no entanto, não se pode constatar efetivamente se houve mudanças qualitativas no quesito aprendizagem da leitura e da escrita atribuídas à existência ou qualificação das bibliotecas nas escolas. Acredita-se que essa lacuna pode ser alvo de pesquisas no sentido de se apurar sobre até que ponto as bibliotecas podem influenciar ou contribuir para uma aprendizagem de qualidade considerando as duas dimensões do PAR que abordam diretamente o assunto, bibliotecas, quais sejam a Dimensão 3 - Práticas pedagógicas e Avaliação e a Dimensão 4 Infraestrutura e Recursos pedagógicos.

A guisa de conclusão, o PAR como um programa governamental tem promovido algumas inquietações sobre os rumos da qualidade da educação brasileira. Entre tantos desafios na transformação da realidade educacional, o mesmo, tem a responsabilidade de levantar e de equacionar as necessidades dos contextos escolares, na maioria das vezes, marcados pelas desigualdades regionais. Como uma política de controle, de repasses de recursos e de responsabilidades o PAR denota uma concepção de qualidade baseada pela racionalidade técnica das informações e dos recursos financeiros destinados à educação, quando, na realidade, deveria contemplar uma concepção de educação de qualidade como um direito social e de cidadania, na qual, todos pudessem usufruir dos recursos e instrumentos da aprendizagem escolar como caminho para melhorar as condições da qualidade de vida em sua totalidade. 
Espaços e Ações das Bibliotecas Escolares no Âmbito do Plano de Ações Articuladas (PAR) do Município de Dourados, MS

\section{Referências:}

AMORIM, M. D. A qualidade da educação básica no PDE: uma análise a partir do Plano de Ações Articuladas. 2011. 165 fls. Dissertação (Mestrado em Educação) - Universidade Federal da Grande Dourados, Dourados, 2011. Disponível em:

<http://www.ufgd.edu.br/faed/mestrado-educacao/dissertacoes-defendidas $>$. Acesso em: 11 out. 2015 .

BRASIL. Lei $\mathrm{n}^{\circ}$ 12.244: Dispõe sobre a universalização das bibliotecas nas instituições de ensino do País. Brasília: Congresso Nacional, 2010. Disponível em:

〈http://www.planalto.gov.br/ccivil_03/_ato2007-2010/2010/lei/112244.htm>. Acesso em: 17 out. 2016.

BRASIL. Ministério da Educação. Instrumento diagnóstico PAR municipal 2011-2014: $6^{\text {a }}$ versão - maio 2011. Brasília: MEC; FNDE, 2011a. Disponível em:

$<$ http://portal.mec.gov.br/index.php?option $=$ com docman\&task $=$ doc _download\&gid=8371\&Itemid=>. Acesso em: 11 out. 2015.

Orientações para elaboração do Plano de Ações Articuladas (PAR) dos municípios (2011-2014): versão preliminar. Brasília: MEC; FNDE, 2011b. Disponível em: $<$ http://www.fnde.gov.br/arquivos/category/129-plano-de-acoes-articuladaspar?download=8133:manual-de-elaboracao-municipal>. Acesso em: 12 dez. 2014.

Orientações gerais para a elaboração do Plano de Ações Articuladas

(PAR). Brasília: MEC, 2008.

PAR - Plano de Ações Articuladas: relatório público, apresentação.

Brasília, DF, 2016. Disponível em:

$<$ http://simec.mec.gov.br/cte/relatoriopublico/impressao.php?inuid=2028\&itrid=2\&est=TO\& mun=Palmas\&municod=1721000\&estuf=TO\&muncod=1721000 > . Acesso em: 10 mar. 2016.

COORDENADORA DO NÚCLEO DE BIBLIOTECA ESCOLAR DA SEMED. [10 nov. 2015]. Entrevistador: Maria do Carmo Caetano. Dourados, MS, 2015. Diário de campo. A entrevista transcrita faz parte dos arquivos da pesquisa CNPq/Fundect $N^{\circ}$ 9/2011 - DCR intitulada: Gestão das políticas educacionais no Brasil e seus mecanismos de centralização e descentralização: o desafio do PAR em escolas de ensino fundamental, sob coordenação da professora Dra. Marília Fonseca (UnB).

CRUZ, R. E. O plano de ações articuladas: desafios para a gestão educacional. Revista Fundamentos, Piauí, v. 2, n. 2, 2015.

DOURADO, Luiz Fernandes. Avaliação do plano nacional de educação 2001-2009: questões estruturais e conjunturais de uma política. Educ. Soc., Campinas, v. 31, n. 112, jul./set. 2010.

DOURADOS. Secretaria Municipal de Educação. Plano de Ações Articuladas2011.pdf. Dourados, MS, 29 de agosto de 2014. 1 arquivo pdf (3,2 mb). Adobe Acrobat.

FEITOSA, M. I. S. O plano de ações articuladas (PAR) na Rede Municipal de Ensino de

Dourados, MS: a qualidade materializada nas práticas pedagógicas do ensino público 
fundamental. 2016. 147f. Dissertação (Mestrado em Educação) - Faculdade de Educação. Universidade Federal da Grande Dourados, Dourados, 2016.

FERREIRA, E. B. Federalismo e planejamento educacional no exercício do par. Cadernos de Pesquisa, São Paulo, v. 44, n. 153, p. 602-623, sept. 2014. Disponível em:

<http://www.scielo.br/scielo.php?script=sci_arttext\&pid=S010015742014000300007\&lng=en\&nrm=iso > . Acesso em: 27 out. 2017

FERREIRA, E. B.; FONSECA, M. Plano de ações articuladas (PAR): discutindo dados da pesquisa em rede. In: (Org.). Política e planejamento educacional no Brasil do século 21. Brasília: Liber Livro, 2013. p. 281-298.

FONSECA, M. Gestão escolar em tempo de redefinição do papel do Estado: planos de desenvolvimento e PPP em debate. Revista Retratos da Escola, Brasília, v. 3, n. 4, p. 185 198, jan./jun. 2009. Disponível em: 〈http://www.esforce.org.br〉. Acesso em: 15 out. 2016.

FONSECA, M.; ALBUQUERQUE, S. V. O PAR como indutor do planejamento da educação municipal. Periódico do Programa de Pós-Graduação da UCDB: Série-Estudos. Campo Grande, n. 34, p. 61-78, jul./dez., 2012.

FREIRE, P. Pedagogia da autonomia: saberes necessários à prática educativa. Paz e Terra, São Paulo, 1996.

MORAES, K. M. K. (Coord.). Padrões mínimos de funcionamento da escola do ensino fundamental: manual de implantação. Brasília, DF: Fundescola/DIPRO/FNDE/ MEC, 2006. Disponível em: <ftp://ftp.fnde.gov.br/web/fundescola/publicacoes_manuais_tecnicos/pmfe_manual_implanta cao.pdf $>$. Acesso em: 17 out. 2016.

PAIVA, J.; BERENBLUM, A. Programa Nacional Biblioteca da Escola (PNBE) - uma avaliação diagnóstica. Pro-posições, Campinas, 2009. Disponível em 〈www.scielo.br/pdf/pp/v20n1/v20n1a10.pdf >. Acesso em: 11 jul. 2016.

SANTOS, C. S. V. O papel do professor bibliotecário: percepções e práticas. 2011. 155 f. Dissertação (Mestrado em Gestão da Informação e Bibliotecas Escolares) - Departamento de Educação e Ensino à Distância. Universidade Aberta, Lisboa, 2011. Disponível em: <http://hdl.handle.net/10400.2/2042>. Acesso em: 11 jul. 2016.

SOUSA, B. J. R. O plano de ações articuladas (PAR) como instrumento de planejamento da educação: o que há de novo? In: SIMPÓSIO BRASILEIRO E CONGRESSO IBEROAMERICANO DE POLÍTICA E ADMINISTRAÇÃO DA EDUCAÇÃO, 25., 2011, São Paulo. Anais... São Paulo: PUC, 2011. p. 1-12. Disponível em: <http://www.anpae.org.br/simposio2011/cdrom2011/PDFs/trabalhoscompletos/comunicacoes Relatos/0079.pdf>. Acesso em: 15 mar. 2016. 